\title{
ELEMENTS OF ELECTRONICS
}

for physical scientists 


\section{A MACMILLAN PHYSICS TEXT}

\section{Other titles}

MODERN ATOMIC PHYSICS: FUNDAMENTAL PRINCIPLES

B. Cagnac and J.-C. Pebay-Peyroula

MODERN ATOMIC PHYSICS: QUANTUM THEORY AND ITS APPLICATIONS

B. Cagnac and J.-C. Pebay-Peyroula

BASIC QUANTUM MECHANICS Second Edition (Revised)

J. M. Cassels

SOLID STATE PHYSICS

A. J. Dekker

SYMMETRY IN PHYSICS, Vol. 1 and Vol. 2

J.P. Elliott and P. G. Dawber

AN INTRODUCTION TO SOLID STATE PHYSICS AND ITS APPLICATIONS

R. J. Elliott and A. F. Gibson

THE SPECIAL THEORY OF RELATIVITY

H. Muirhead

FORCES AND PARTICLES

A. B. Pippard

THERMAL PHYSICS

P. C. Riedi

INTRODUCTION TO NUCLEAR REACTIONS

G. R. Satchler

ORBITALS AND SYMMETRY

D. S. Urch 


\title{
Elements of Electronics for physical scientists
}

\author{
R. L. HAVILL and A. K. WALTON \\ Department of Physics, University of Sheffield
}

Second Edition

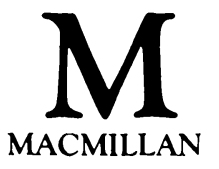


○ R. L. Havill and A. K. Walton 1975,1985

Softcover reprint of the hardcover 1st edition 1975

All rights reserved. No reproduction, copy or transmission of this publication may be made without written permission.

No paragraph of this publication may be reproduced, copied or transmitted save with written permission or in accordance with the provisions of the Copyright Act 1956 (as amended).

Any person who does any unauthorised act in relation to this publication may be liable to criminal prosecution and civil claims for damages.

First edition 1975

Reprinted 1980

Second edition 1985

Published by

Higher and Further Education Division

MACMILLAN PUBLISHERS LTD

Houndmills, Basingstoke, Hampshire RG21 2XS

and London

Companies and representatives

throughout the world

British Library Cataloguing in Publication Data

Havill, R. L.

Elements of electronics for physical scientists.

- (A Macmillan physics text) - 2nd ed.

1. Electronic apparatus and appliances

I. Title II. Walton, A. K.

$621.381^{\prime} 02453$ TK7870

ISBN 978-0-333-35917-4

ISBN 978-1-349-18009-7 (eBook)

DOI 10.1007/978-1-349-18009-7 


\section{Contents}

1 Semiconductors and P-N Junctions 1

1.1 Energy-band Theory of Electrical Conduction 1

1.2 Effective-mass Concept 4

$\begin{array}{lll}1.3 & \text { Positive-hole Concept } & 7\end{array}$

1.4 Conductivity and Mobility 7

1.5 Extrinsic Semiconductors $\quad 8$

$\begin{array}{lll}1.6 & \text { The Fermi Level } & 10\end{array}$

1.7 Fermi Level in Inhomogeneous Semiconductors 15

$\begin{array}{lll}1.8 & \text { The P-N Junction } & 16\end{array}$

1.9 Reverse Saturation Current 21

$\begin{array}{ll}1.10 \text { Injection } & 23\end{array}$

1.11 The Depletion Region 25

$\begin{array}{ll}1.12 \text { Diffusion or Storage Capacitance } & 27\end{array}$

$\begin{array}{ll}1.13 \text { Ohmic Contacts } & 29\end{array}$

2 Diodes and their Circuits $\quad 32$

$\begin{array}{ll}2.1 \text { Introduction } & 32\end{array}$

2.2 Half-wave Rectification $\quad 33$

$\begin{array}{lll}2.3 & \text { Full-wave Rectification } & 35\end{array}$

2.4 D.C. Power Supplies from A.C. Sources 36

2.5 Filters for Power Supplies $\quad 39$

$\begin{array}{ll}2.5 .1 \text { Inductor filter } & 39\end{array}$

2.5.2 L-section or inductor-input filter $\quad 40$

$2.5 .3 \pi$-section filters $\quad 41$

2.6 Zener Diodes $\quad 41$

2.7 Polyphase Rectifier Circuits 44

2.8 Voltage-multiplier Circuits $\quad 45$ 
2.9 Diode Clippers $\quad 45$

2.10 Diode Clamps $\quad 46$

$\begin{array}{ll}2.11 \text { A.C. Meters } & 47\end{array}$

2.12 Frequency Mixing $\quad 48$

2.13 Amplitude Modulation $\quad 49$

$\begin{array}{ll}2.14 \text { Demodulation } & 50\end{array}$

2.15 Frequency-modulated Signals and their Detection 51

2.16 Phase-sensitive Detection $\quad 55$

3 The Junction Transistor $\quad 57$

$\begin{array}{ll}3.1 \text { Physical Operation } & 57\end{array}$

$\begin{array}{lll}3.2 & \text { Junction-transistor Fabrication } & 60\end{array}$

3.3 Mesa and Planar Transistors $\quad 64$

$\begin{array}{lll}3.4 & \text { Current Gain } & 65\end{array}$

3.5 Minority-carrier Diffusion in the Base and High-frequency
Limitations

4 Small-signal Analysis $\quad \mathbf{7 5}$

4.1 Electronic-system Parameters $\quad 75$

4.2 Static Characteristics of the Junction Transistor in the

Common-base Configuration 80

4.3 The Common-base T-equivalent Circuit $\quad 81$

4.4 Transistor Symbols and Configurations $\quad 84$

4.5 Analysis of the Common-emitter Configuration Using the

4.6 The Hybrid Equivalent Circuit $\quad 89$

4.7 Common-collector $h$-parameters in Terms of Common-emitter $h$-parameters $\quad 90$

4.8 Small-signal Analysis Using the Hybrid Equivalent Circuit 92

4.9 Summary of Transistor Configuration Properties 94

5 Single-stage Amplifiers $\quad 95$

5.1 Operating Point and Large-signal Analysis 95

5.2 Classes of Operation $\quad 97$

$\begin{array}{lll}5.3 \text { Simple Biasing } & 100\end{array}$

5.4 Stabilisation of the Operating Point 103

5.5 Practical Stabilised Amplifier Stages 106

$\begin{array}{lll}5.6 & \text { Distortion } & 110\end{array}$

5.7 Class B Push-Pull Amplifiers 111

$\begin{array}{lll}5.8 \text { Noise } & 114\end{array}$

5.9 High-frequency Response 116

5.10 Summary of Design Considerations 125 
6 Multistage Amplifiers $\quad 126$

$\begin{array}{lll}6.1 \text { Introduction } & 126\end{array}$

$\begin{array}{ll}6.2 \text { Capacitor Coupling } & 127\end{array}$

$\begin{array}{lll}6.3 & \text { Transformer Coupling } & 130\end{array}$

6.4 Tuned Amplifiers 133

7 Feedback 136

$\begin{array}{lll}7.1 & \text { Definitions and Objectives } & 136\end{array}$

7.2 Analysis of Circuit Models for Feedback 138

7.3 Application of Negative Feedback to Single-stage Amplifiers 142

7.4 Application of Negative Feedback to Multistage Amplifiers 145

$\begin{array}{lll}7.5 & \text { Circuit Instability } & 148\end{array}$

7.6 Bootstrapping and the Compound Emitter-follower 151

8 D.C. Amplification and Operational Amplifiers 154

$\begin{array}{lll}8.1 \text { General Survey } & 154\end{array}$

$\begin{array}{ll}8.2 \text { Basic Considerations } & 154\end{array}$

8.3 The Long-tailed Pair 156

8.4 Operational Amplifiers 162

$\begin{array}{ll}8.5 & 163\end{array}$

$\begin{array}{ll}8.6 \text { Noninverting Configuration } & 168\end{array}$

$\begin{array}{ll}8.7 \text { Compensation and Offsets } & 170\end{array}$

8.8 Basic Applications of Operational Amplifiers 173

8.9 Chopper Amplifiers $\quad 180$

9 Sinusoidal Oscillators $\quad 182$

$\begin{array}{lll}9.1 & \text { R-C Tuned Sinusoidal Oscillators } & 182\end{array}$

9.2 L-C Tuned Sinusoidal Oscillators $\quad 186$

$\begin{array}{ll}9.3 \text { Crystal Oscillators and Stability } & 189\end{array}$

9.4 The Quadrature Oscillator 192

10 Switching Circuits 193

10.1 Introduction $\quad 193$

10.2 The Transistor as a Switch 194

10.3 The Bistable Multivibrator $\quad 197$

10.4 The Monostable Multivibrator 202

10.5 The Astable Multivibrator 205

10.6 The Schmitt Trigger $\quad 207$

10.7 Switching with Operational Amplifiers $\quad 210$

$\begin{array}{ll}10.8 \text { Switching Complex Loads } & 214\end{array}$ 
11 Digital Logic $\quad 216$

11.1 Basic Logic Functions $\quad 216$

$\begin{array}{ll}11.2 \text { Gate Circuitry } & 219\end{array}$

11.3 Venn Diagrams and Boolean Algebra 224

11.4 Design of Combinational Logic Circuits 228

11.5 Exclusive-OR, Exclusive-NOR and Arithmetic Circuits 232

11.6 Flip-flops and other Multivibrator Logic 235

11.7 Drivers, Buffers and Bus Sharing 240

12 Field-effect Transistors and Thermionic Valves 243

12.1 The Junction-gate Field-effect Transistor 243

12.2 Development of the Physical Theory of the JFET 247

12.3 Metal-oxide-semiconductor Field-effect Transistors 252

12.4 Circuit Aspects of FETs $\quad 261$

12.5 Thermionic Valves 268

13 Integrated-circuit Technology 275

13.1 Doping by Diffusion 276

13.2 Ion Implantation $\quad 278$

$\begin{array}{ll}13.3 \text { Epitaxial Growth } & 279\end{array}$

13.4 Monolithic Integrated Circuits $\quad 280$

13.5 Monolithic Components 283

13.6 Film Components 286

$\begin{array}{ll}13.7 \text { Packaging } & 287\end{array}$

13.8 Schottky Diodes and Transistors $\quad 289$

13.9 Charge-coupled Devices 292

14 Negative-resistance Devices 296

14.1 Tunnel Diodes 296

14.2 The Unijunction Transistor 298

14.3 Thyristors and Associated Devices $\quad 300$

$\begin{array}{ll}\text { 14.4 The Gunn Effect } & 307\end{array}$

$\begin{array}{ll}14.5 \text { Avalanche Diodes } & 309\end{array}$

14.6 Parametric Amplifiers $\quad 312$

15 Masers, Lasers and Optoelectronics 315

$\begin{array}{ll}15.1 \text { Masers and Lasers } & 315\end{array}$

15.2 The P-N Junction Laser $\quad 318$

$\begin{array}{ll}15.3 \text { Light-emitting Diodes } & 322\end{array}$

15.4 Electronic Displays $\quad 324$

$\begin{array}{ll}15.5 \text { Photodetectors } & 329\end{array}$

15.6 Miscellaneous Optoelectronic Applications 333 
16.1 Stabilised Power Supplies 338

16.2 The Phase-sensitive Amplifier 345

16.3 Radio Receivers 347

16.4 An Audio Power Amplifier 351

16.5 A Decade Counter 353

16.6 Digital-to-analogue Converters 357

16.7 Analogue-to-digital Converters 360

16.8 Digital Voltmeters 363

17 Laboratory Exercises 366

Equipment and Practical Tips 366

1 R-C Networks (4 hours) 369

2 Rectifier Circuits (4 hours) 373

3 Static Characteristics of P-N Junction Diodes (5 hours) 374

4 Static Characteristics of Junction Transistors (4 hours) 376

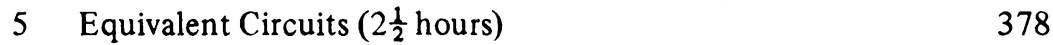

6 Load-line Analysis (1 $1 \frac{1}{2}$ hours) 379

7 Simple Biasing of Junction Transistors (3 hours) 379

8 Signal Properties of Single-stage Amplifiers (2 hours) 380

9 Thermal Stabilisation of Junction-transistor Amplifier Stages (3 hours) 381

10 Multistage Amplifiers (3 hours) 381

11 Negative Feedback (4 hours) 382

12 Darlington Connection and Bootstrapping (2 hours) 385

13 The Long-tailed Pair (3 hours) 385

$14 \begin{aligned} & \text { Negative-feedback Applications of Operational Amplifiers } \\ & \text { (7 hours) }\end{aligned}$

15 Positive Feedback and Oscillation (4 hours) 388

16 Transistor Switching (7 hours) 389

17 Switching Applications of Operational Amplifiers (3 hours) 391

18 Gates and Combinational Logic (6 hours) 392

19 Flip-flops and Sequential Logic (3 hours) 394

20 Counters (3 hours) 395

21 Shift Registers and Arithmetic Operations (4 hours) 396

22 Field-effect Transistors (5 hours) 396

23 Negative-resistance Devices (4 hours) 398

24 Stabilised Power Supply (3 hours) 399

25 D/A and A/D Converters (4 hours) 400

18 Solutions to and Comments on the Laboratory Exercises 402

1 R-C Networks 402

2 Rectifier Circuits 404 
3 Static Characteristics of P-N Junction Diodes 406

4 Static Characteristics of Junction Transistors 407

5 Equivalent Circuits $\quad 407$

6 Load-line Analysis 408

7 Simple Biasing of Junction Transistors 409

8 Signal Properties of Single-stage Amplifiers 409

9 Thermal Stabilisation of Junction-transistor Amplifier Stages 410

10 Multistage Amplifiers 411

11 Negative Feedback $\quad 412$

12 Darlington Connection and Bootstrapping 413

13 The Long-tailed Pair 414

14 Negative Feedback Applications of Operational Amplifiers 415

15 Positive Feedback and Oscillation 418

16 Transistor Switching 419

17 Switching Applications of Operational Amplifiers 421

18 Gates and Combinational Logic 422

19 Flip-flops and Sequential Logic 422

20 Counters 423

21 Shift Registers and Arithmetic Operations 423

22 Field-effect Transistors $\quad 424$

23 Negative-resistance Devices $\quad 426$

24 Stabilised Power Supply 428

$25 \mathrm{D} / \mathrm{A}$ and A/D Converters 430

Appendix 1 Introduction to Fourier Analysis 431

Appendix 2 Space-charge Neutrality in Semiconductors 435

Appendix 3 Signal Properties of Transistor Configurations 438

Appendix 4 Approximate Conversion Relations among the $h$ and 440

T-equivalent Circuit Parameters

Appendix 5 Thévenin and Norton Theorems 442

$\begin{array}{ll}\text { Index } & 445\end{array}$ 


\section{Preface to First Edition}

The growth of electronics during the past three decades has been prolific. There have been far-reaching social and domestic repercussions and the adoption of electronic techniques by scientists has become commonplace. This book is intended to provide an introductory course for students who are at about first or second-year University level but are not specialising in electronics. It has been written primarily with physical scientists in mind and a corresponding knowledge of physics and mathematics is taken for granted. In particular, familiarity with alternating-current theory including important network ideas such as that embodied in Thévenin's theorem is assumed and an acquaintance with quantum ideas and electromagnetic theory is expected.

The interest of physical scientists in electronics is twofold. Firstly, there is a desire to understand and apply relevant electronic circuits to facilitate the execution of experiments. Secondly, there is a wish to understand the physical operation of the active devices involved. In writing a book it is difficult to strike a balance between these objectives. The authors have chosen to bias the contents of this volume in the direction of circuit electronics in the belief that this represents the greater interest of the majority of scientists in electronics. Emphasis is placed on understanding and designing basic circuits rather than complete systems, although this important topic is broached near the end of the book. The authors are also of the opinion that beginners are generally overwhelmed by large textbooks and the present text has therefore been restricted to about 300 pages. Sufficient physical theory for introductory purposes is presented in just three chapters. Within the limited space, a simple explanation of as wide a variety of devices and electronic methods as possible has been considered to be more important than a detailed treatment of any particular topic. Accordingly, it has not been possible to develop some aspects of the subject to what might be termed a 'professional level'.

A decision to develop the theory of electronic circuits in terms of the bipolar transistor was taken for the following reasons. Development of electronic theory in terms of more than one device at a time often leads to confusion and is 
wasteful in space. At present, the bipolar transistor is by far the most widely used discrete component. It has a more general low-frequency equivalent circuit than other active devices such as the field effect transistor or the thermionic valve and is clearly the most sensible choice. In view of this approach, thermionic valves and field-effect transistors and their circuits are discussed in a separate chapter.

Despite the fact that integrated circuits are coming into widespread use, attention has been concentrated on circuits built from discrete components since the prime concern of this book is to explain the action of basic circuits. Consideration of integrated circuits adds nothing to basic understanding; they are essentially a matter of detailed technology. It has been thought worth while, however, to draw attention to a few particular integrated circuits in relevant parts of the text and to outline their method of fabrication.

Above all else, electronics is a practical subject and it is vital that in parallel with any theoretical study, practical experience is gained by investigating real devices and by building, testing and measuring the properties of real circuits. Discrete components such as transistors, resistors and capacitors are essential for this purpose. A series of laboratory exercises has been devised and it is suggested that these are followed in parallel with reading the theoretical chapters. Solutions to and comments on these exercises are provided. The very first exercise on $\mathrm{R}-\mathrm{C}$ networks should reveal the advantage of a laboratory approach to learning the subject. Laboratory work should not be a minor adjunct to theoretical study; it is crucially important in its own right. In the physics department at Sheffield University the exercises occupy about thirty laboratory periods of three hours each, while the theoretical chapters are covered in about forty lectures.

In the interest of clarity, some circuits in the text have been simplified. Often the simplification is just the adoption of simple biasing rather than a stabilised arrangement. Such simplifications are pointed out throughout the text.

We would like to acknowledge the provision of facilities in the physics department at Sheffield, not to mention the unwitting co-operation of undergraduate students, both of which have been invaluable in developing the laboratory exercises. Particular thanks are due to Mrs L. Ottiwell and Mrs J. S. P. Appleby for their assistance with the preparation of the figures and manuscript.

Physics Department, University of Sheffield, 1975
R. L. Havill

A. K. Walton 


\section{Preface to Second Edition}

Since publication of the first edition, electronics has continued to evolve explosively, mainly as a result of the continual improvement and increased application of integrated circuits. Notwithstanding the chip revolution, the authors still believe that basic electronics is best taught through circuits built from discrete components so that their design and operation can be thoroughly studied. The second edition consequently retains the initial development of the key electronic functions of linear application and switching in terms of the junction transistor. However, the early chapters now lead on to integrated-circuit forms of amplifiers, oscillators and logic, reflecting current practice. Much of the middle of the book has been rewritten to this end. In particular, the chapter on 'Digital Logic' is extensively revised and extended while a new chapter on 'Integrated-circuit Technology' has been added. It has also proved beneficial to regroup the topics of feedback and d.c. amplification into three chapters, namely 'Feedback', 'D.C. Amplification and Operational Amplifiers' and 'Sinusoidal Oscillators'.

While updating and re-organising the second edition, the opportunity has been taken to strengthen several areas. For example, a much better treatment of the high-frequency behaviour of transistors is presented and a more general view of feedback is offered. Operational amplifiers are afforded much greater coverage, more extensive quantitative physical theories of the JFET and MOSFET are introduced and Thevenin's theorem is included as an appendix. The rapidly developing field of optoelectronics now merits a separate chapter and a greater variety of systems is considered in the concluding theoretical chapter.

To match the increased content, the number of laboratory exercises has been increased from 19 to 25 . However, throughout the revision, the need to keep the length of the text within reasonable bounds has been constantly borne in mind, as has the objective of as wide a coverage of topics as possible. Sections that could be omitted on the first reading without compromising development of basic understanding are marked with a single asterisk or a double asterisk when also rather difficult.

Provision of facilities in the physics department at Sheffield is again gratefully acknowledged. In particular, we are indebted to Mr J. C. Newell for occasional help with circuit testing and to Mrs K. Battye and Mrs S. Stapleton for their considerable assistance in preparing the figures and manuscript.

Physics Department, R. L. Havill University of Sheffield, A. K. Walton 1984 